\title{
Studi Eksperimen Pengaruh Variasi Perubahan Refrigeran-22 Dengan Musicool-22 Pada Sistem Pengkondisian Udara Dengan Pre-cooling
}

\author{
Arnovia Christine Sabatiana dan Ary Bachtiar Krishna Putra \\ Jurusan Teknik Mesin, Fakultas Teknologi Industri, Institut Teknologi Sepuluh Nopember (ITS) \\ Jl. Arief Rahman Hakim, Surabaya 60111 Indonesia \\ e-mail: ary_bachtiar@me.its.ac.id
}

\begin{abstract}
Abstrak- Air conditioning system merupakan mesin sistem refrigerasi kompresi uap sederhana. Kemudian dimodifikasi menjadi dua indoor unit dan satu outdoor unit. Dimana outdoor unit memiliki dua jenis kondenser yaitu, water cooled condenser dan air cooled condenser. Pembuangan kalor pada bagian water cooled condenser dimanfaatkan untuk memanaskan air yang nantinya dapat digunakan untuk kebutuhan sehari-hari kedepannya. Penggunaan refrigeran CFC atau HCFC mengakibatkan beberapa dampak negatif terhadap lingkungan dan penggunaan mesin refrigerasi ini, diantaranya dapat merusak lapisan ozone, pemanasan global dan tidak hemat energi listrik. Penelitian pada ini adalah untuk menganalisis dan membandingkan performansi suatu sistem refrigerasi sederhana yang mampu menghemat konsumsi energi dan ramah lingkungan. Metoda penelitian ini dilakukan pertama menggunakan R-22 sebagai refrigeran primernya dan selanjutnya dilakukan proses retrofitting (penggantian refrigeran) dengan menggunakan MC-22. Selanjutnya analisis dilakukan berdasarkan data dari setiap titik-titik pengukuran dengan begitu akan diperoleh suatu sistem refrigerasi dengan performansi yang paling baik dengan konsumsi energi listrik yang sedikit, serta sistem refrigerasi yang ramah lingkungan. Sistem tersebut aladah yang menggunakan MC-22 baik menggunakan atau tanpa pre-cooling dengan nilai COP elektrik 3,786; dan 3,933, COPthermal 4,501; dan 4,670, dan nilai penghematan energi listrik sekitar $20 \%$ lebih hemat dibanding sistem yang menggunakan R-22.
\end{abstract}

Kata Kunci- air conditoning system, efesiensi, MC-22, retrofitting, $\mathbf{R}-22$.

\section{PENDAHULUAN}

$\mathrm{D}$ EWASA ini perkembangan teknologi diberbagai bidang semakin pesat, salah satunya dalam bidang refrigerasi. Salah satu sistem pendingin yang banyak digunakan pada saat ini yaitu air conditioning sistem. Kemudian mesin air conditioning ini dimodifikasi yang didalamnya terdapat dua indoor unit dan satu outdoor unit. Dimana outdoor unit memiliki dua jenis kondenser yaitu, water cooled condenser dan air cooled condenser dan pembuangan kalor pada bagian water cooled condenser dimanfaatkan untuk memanaskan air yang nantinya dapat digunakan untuk kebutuhan sehari-hari kedepannya.

Pada umumnya jenis refrigeran yang digunakan pada air conditioning sistem adalah refrigeran jenis Cloro Fluoro Carbon (CFC) yang tidak ramah terhadap lingkungan. Sehingga berdampak pada lingkungan hidup karena penggunaannya dapat mengakibatkan penipisan lapisan ozon yang dirusak oleh gas-gas klorine yang dilepaskan secara sengaja oleh manusia maupun melalui proses alami. Lapisanlapisan ozon yang diikat oleh klorine akan terus menerus mengikat ozon yang lain dan menyebabkan ozon terurai menjadi $\mathrm{O}_{2}$. Untuk mengatsi masalah perusakan lapisan ozon, dan pemanasan global dikalangan masyarakat saat ini maka dilakukan pencegahan untuk mengurangi perusakan yang terjadi. Salah satunya dilakukan proses penggantian jenis refrigeran yang diaplikasikan pada mesin ini, proses ini dilakukan pada sistem refrigerasi kompresi uap yang sebelumnya menggunakan refrigeran-22 menjadi sistem refrigerasi kompresi uap yang menggunakan refrigeran ramah lingkungan yaitu dengan refrigeran hydrocarbon propane (MC-22).

Diharapkan pula konsumsi energi listrik yang digunakan akan lebih hemat dibandingkan dengan sebelumnya, karena MC-22 memiliki sifat termodinamika yang berbeda dibandingkan dengan refrigeran-22 maka akan berdampak pula terhadap nilai efek refrigerasi yang diperoleh antara sistem refrigerasi sebelum dan sesudah mengalami perubahan jenis refrigeran sehingga nilai COP dan nilai efisiensi dari sistem refrigerasi dapat dianalisis untuk memperoleh nilai performansi dari sistem.

\section{URAIAN PENELITIAN}

\section{A. Refrigeran}

Refrigeran berfungsi sebagai media pendingin dengan menyerap kalor dari benda atau bahan lain, seperti air atau udara di ruangan sehingga refrigeran tersebut dapat dengan mudah merubah fasanya dari cair menjadi gas. Sedangkan pada saat terjadi pelepasan kalor oleh refrigeran terjadi perubahan fasa dari gas bertekanan tinggi jenuh menjadi cair. Dalam pemilihan refrigeran harus memperhatikan tekanan kondensasi, pemilihan NBP (normal boiling point), dan keamanan.

Pada awalnya sistem refrigerasi kompresi uap menggunakan sulfur dioksida, metilklorida dan amonia. Namun ternyata semuanya merupakan bahan yang beracun dan membahayakan, maka dari itu sulfur dioksida dan metil klorida dihilangkan dari pasaran dan sudah tidak lagi ditemukan dengan diperkenalkannya CFC (Chloro Fluoro 
Carbons). Penggunaan Chloro Fluoro Carbons masih sedikit di kalangan masyarakat sampai ditemukannya metode yang lebih baik pada tahun 1950, tetapi pada tahun 1980 dominasinya dipertanyakan karena kekhawatiran tentang penipisan lapisan ozon dampak yang terjadi pada lingkungan akibat penggunaan Chloro Fluoro Carbons.

\section{B. Refrigeran-22}

R-22 merupakan refrigeran yang memiliki rumus kimia CHCLF2 atau (Chloro Diffluoro Methane). R-22 memegang peranan penting dalam sistem refrigerasi, sejak ditemukan pada tahun 1930. Hal ini dikarenakan CFC (Chloro Fluoro Carbon) atau R-22 memiliki properti fisika dan termal yang baik sebagai refrigeran, stabil, tidak mudah terbakar, tidak beracun dan kompatibel terhadap sebagian besar bahan komponen dalam sistem refrigerasi.

Akan tetapi masyarakat mengetahui bahwa CFC termasuk Ozone Depleting Substance (ODS), yaitu zat yang dapat menyebabkan kerusakan ozon, masyarakat mulai mencoba melakukan penghentian pemakaian ODS dan dituangkan kedalam beberapa konvensi seperti Vienna Convention pada bulan Maret 1985, Montrean Protocol pada bulan September 1987, dan beberapa amandemen lainnya [1].

\section{Musicool-22}

Dengan dihapuskanya penggunaan refrigeran penyebab perusak lapisan Ozone (Ozone Depletion Potensial/ODP) dan penyebab peningkatan panas bumi (Global Warming Potensial/GWP) maka beberapa refrigeran pengganti yang ramah lingkungan telah dipilih dan dilakukan penelitian di beberapa laboratorium di berbagai Negara. (Nasruddin\&Hamdi,2003) [3].

Refrigeran pengganti yang digunakan yaitu hidrokarbon yang diteliti pertama kali oleh ilmuan Linde (1916) dan ilmuan Albert Einstein (1920) karena hidrokarbon pada sistem refrigerasi telah dikenal sejak tahun 1920-an. Karena 99,7\% komposisi dari Musicool-22 adalah propana, maka Musicool dapat juga disebut sebagai Propane (Aneka Firdaus, 2010) [2]. Pada zaman sekarang hidrokarbon dipertimbangkan kembali setelah terjadi isu penipisan ozon dan pemanasan global.

\section{Sistem Refrigerasi Kompresi Uap Sederhana}

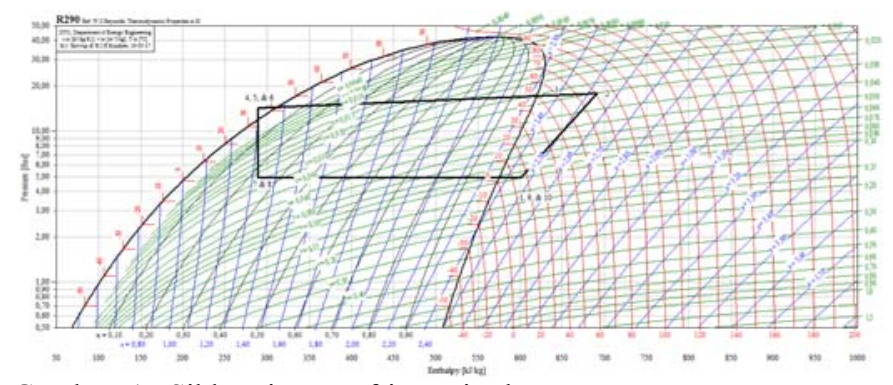

Gambar. 1. Siklus sistem refrigerasi sebenarnya

Sistem refrigerasi kompresi uap adalah sistem refrigerasi yang paling sederhana. Sistem refrigerasi kompresi uap ini memiliki empat komponen utama diantaranya: kompresor, condenser, alat ekspansi, evaporator. Proses kompresi uap tersebut berlangsung secara terus menerus di dalam P-h diagram seperti yang ditunjukan pada gambar 1 .

\section{E. Coefficient of Performance (COP)}

Unjuk kerja mesin dinyatakan dengan efesiensi termal. Unjuk kerja mesin refrigerasi atau pompa kalor dinyatakan dengan perbandingan kalor yang dimanfaatkan (diserap/dilepaskan oleh sistem) terhadap kerja yang dilakukan, disebut sebagai rasio energi atau koefisien unjuk kerja/prestasi (COP).

$$
\begin{aligned}
& C O F=\frac{\text { Energl yang ternanfaathan }}{\text { Energi yang digunakan sebagai kerfa }}
\end{aligned}
$$

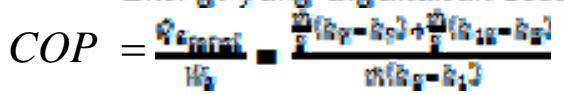

Untuk menghitung suatu prestasi ideal mesin refrigerasi berdasarkan nilai $\mathrm{COP}_{\text {aktual }}$ sebagai berikut :

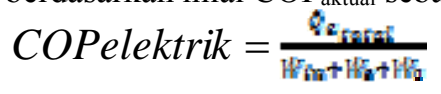

\section{F. Metode Number of Transfer Unit (NTU)}

Untuk mengevaluasi kinerja heat exchanger tipe concentric tube digunakan metode Number of Transfer Units (NTU). Untuk mengetahui kinerja heat exchanger maka dapat digunakan effectiveness dari heat exchanger itu sendiri. Untuk mencari hal tersebut maka harus diketahui nilai perpindahan kalor maksimum $\left(\mathrm{q}_{\max }\right)$ dari heat exchanger.

Untuk nilai $\mathrm{C}_{\mathrm{c}}<\mathrm{C}_{\mathrm{h}}$, maka,

$$
q_{\max }=C_{e}\left(T_{\text {mit }}-T_{\theta, t}\right)
$$

Untuk nilai $\mathrm{C}_{\mathrm{h}}<\mathrm{C}_{\mathrm{c}}$, maka,

$q_{\text {max }}=C_{h}\left(T_{h_{r}-t}-T_{q_{i}}\right)$

dimana untuk nilai $G_{q}=m_{q}, G_{g} \varepsilon$ dan $G_{h}=m_{h}, G_{g} h$.

Nilai $C_{\min }$ adalah sama dengan nilai $C_{c}$ atau $C_{h}$ tergantung mana yang nilainya lebih kecil.

Untuk menentukan effectiveness ( $\varepsilon$ ) dari heat exchanger dapat diperoleh dengan membandingkan antara nilai perpindahan panas aktual dengan nilai perpindahan panas maksimum sebagai berikut :

$$
\begin{aligned}
& s=\frac{q}{q_{\max }}
\end{aligned}
$$

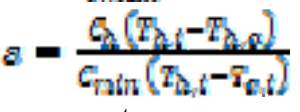

$$
\begin{aligned}
& \text { atau }
\end{aligned}
$$

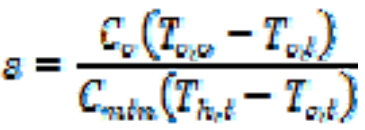

Untuk nilai NTU pada heat exchanger tipe concentric tube dengan jenis aliran counter dapat digunakan perumusan sebagai berikut :

$$
\begin{aligned}
& N T U=\frac{1}{G_{r}-1} \ln \left(\frac{a-1}{a G_{\gamma}-1}\right), \text { untuk }\left(\mathrm{C}_{\mathrm{r}}<1\right) \\
& \text { atau } \\
& N T U=\frac{\mathfrak{z}}{1-2}, \text { untuk }\left(\mathrm{C}_{\mathrm{r}}=1\right)
\end{aligned}
$$




\section{METODOLOGI}

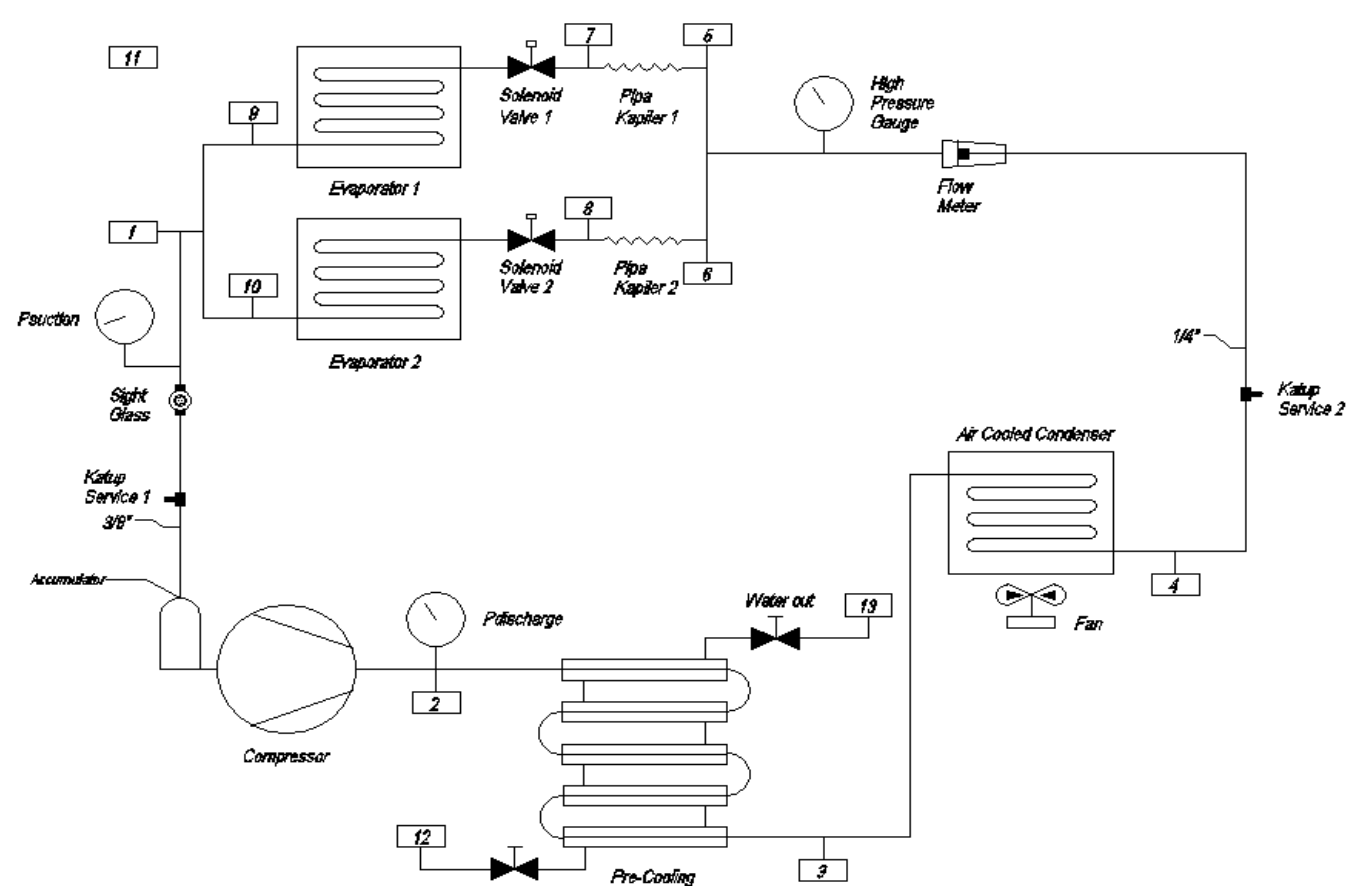

Gambar. 2. Diagram blok pemipaan yang dimodifikasi

A. Perancangan Pre-cooling

Langkah-langkah dalam perancangan sebagai berikut:

1. Menentukan kapasitas dari pre-cooling, temperatur masuk refrigeran, temperatur keluar refrigeran,temperatur masuk air, temperatur keluar air, diameter dalam, diameter luar.

2. Menghitung $\Delta T_{l m}$.

3. Menghitung bilangan reynold refrigeran dan menghitung diameter hidrolis pipa annulus.

4. Menghitung bilangan nusselt refrigeran dan bilangan reynold air.

5. Menghitung nilai koefisien konveksi refrigen dan nilai koefisien konveksi air.

6. Menghitung nilai overall heat transfer.

7. Menghitung panjang pipa yang dibutuhkan untuk alat penukar panas tipe concentric.

\section{B. Alat yang Digunakan}

Proses studi eksperimen dan analisis pada mesin rerfigerasi air conditioning yang pertama dilakukan adalah observasi terhadap dimensi mesin, kemudian dilakukan proses penggatian antara refrigeran-22 dengan musicool-22. Mesin yang digunakan merupakan mesin air conditioning yang telah dimodifikasi menjadi dua indoor unit dan satu outdoor unit. Dimana outdoor unit memiliki dua jenis kondenser yaitu, water cooled condenser dan air cooled condenser dan pembuangan kalor pada bagian water cooled condenser dimanfaatkan untuk memanaskan air sehingga dilakukan proses rancang bangun terlebih dahulu.

\section{Alat Ukur yang Digunakan}

Alat ukur yang digunakan untuk mengambil data dengan menentukan titik ukur yang tepat maka hasil yang didapatkan akan digunakan untuk bahan studi eksperimen dan analisis performansi memiliki nilai yang tepat. Alat ukur yang terdapat pada sistem adalah high-low pressure gauge, clamp-on ammeter digital, flowmeter, thermocouple, dan data akusisi.

Sesuai dengan titik pengukuran sebagai berikut:

- $\mathrm{T} 1=$ Temperatur suction

- $\mathrm{T} 2$ = Temperatur discharge

- $\mathrm{T} 3=$ Temperatur out water cooled condenser

- T4 = Temperatur out air cooled condenser

- T5 = Temperatur in pipa kapiler 1

- $\mathrm{T} 6$ = Temperatur in pipa kapiler 2

- $\mathrm{T} 7$ = Temperatur out pipa kapiler 1

- T8 = Temperatur out pipa kapiler 2

- $\mathrm{T} 9=$ Temperatur out evaporator 1

- $\mathrm{T} 10=$ Temperatur out evaporator 2

- $\mathrm{T} 11=$ Temperatur lingkungan

- $\mathrm{T} 12=$ Temperatur in water

- $\mathrm{T} 13=$ Temperatur out water

- Ps = Tekanan suction

- $\mathrm{Pd}=$ Tekanan discharge

- $\mathrm{Ph}=$ Tekanan setelah air cooled condenser

D. Langkah-langkah Penelitian

Langkah-langkah yang dilakukan dalam penelitian ini adalah lakukan prosedur pemvakuman yang baik dan benar sesuai dengan langkah-langkah yang sudah ditetapkan terhadap sistem refrigerasi hingga mencapai nilai tekanan di 
bawah minus 1 bar sebelum melakukan pengisian refrigeran primer R-22. Kemudian timbang tabung refrigeran primer R22 berwarna hijau diatas timbangan elektronik dan catat berat awalnya. Pasang dan hubungkan slang ke tabung refrigeran primer R-22. Lakukan flushing yaitu membuang sedikit refrigeran. Hubungkan ujung slang yang lain ke saluran suction pada AC Split, kemudian buka katup tabung refrigeran sedikit lebih besar dan refrigeran akan masuk ke dalam sistem refrigerasi. Jika tekanan discharge telah sesuai, lalu tutup katup tabung refrigeran, hidupkan sistem refrigerasi. Setelah pengisian cukup, tutup tabung refrigeran kembali dan tutup katup servis pada saluran suction (CW). Kemudian catat berat tabung yang tersisa. Jika semua prosedur telah dilaksanakan maka jalankan sistem dan lakukan pengambilan data sesuai dengan data yang telah disiapkan. Begitu juga langkahlangkah yang dikerjakan pada saat penggantian refrigerant menggunakan $\mathrm{MC}-22$, namun pada saat proses pengisian jumlah massa refrigeran MC-22 sama dengan $46.6 \%$ berat pengisian R-22 . Nilai $46.6 \%$ tersebut didapat dari hasil massa jenis MC-22 dibagi massa jenis R-22 dikali 100\% (pada saat kondisi uap, massa jenis R-22 : $44.232 \mathrm{~kg} / \mathrm{m}^{3}$ dan MC-22 : $20.646 \mathrm{~kg} / \mathrm{m}^{3}$ (Refprop 2007)

\section{ANALISIS DAN PEMBAHASAN}

Pada proses analisis merupakan proses pengolahan semua data hasil pengamatan dan yang pada akhirnya akan dijadikan pembahasan. Pengolahan data ini menggunakan aplikasi refprop sehingga dengan mengggunakan aplikasi ini dapat diketahui nilai entalpi. Selain menggunakan aplikasi, pengolahan data dilakukan dengan mengeplot data yang dimiliki ke diagram pressure-entalphy. Data hasil pengujian dapat dilihat pada lembar lampiran.

\section{A. Kinerja Sistem Elektrik vs Kapasitas Kondensasi}

Berikut ini adalah grafik $\mathrm{COP}_{\text {elektrik }}$ (coefficient of performance) terhadap kalor yang dilepaskan oleh condenser (kapasitas kondensasi) apabila dibandingkan saat tidak menggunakan pre-cooling dansaat menggunakan precooling adalah sebagai berikut :

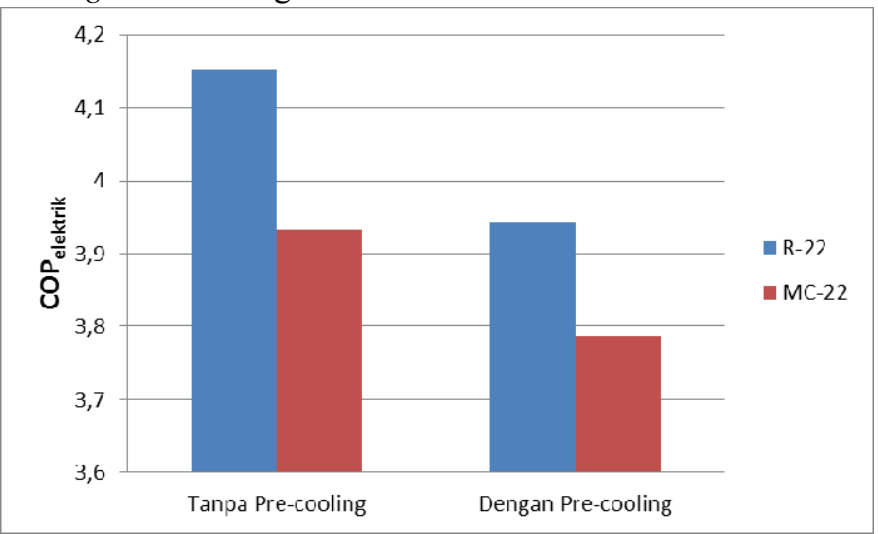

Gambar. 3. Perbandingan COPelektrik antara R-22, R-22 dengan penambahan pre-cooling, MC-22, dan MC-22 dengan penambahan pre-cooling.

Pada grafik tampak bahwa sistem yang menggunakan R-22 menunjukan nilai nilai koefisien yang lebih besar yaitu ratarata 4,151 dan bila dibandingkan dengan sistem yang menggunakan MC-22 rata-rata nilai koefisien yaitu 3.933. Begitu juga dengan sistem yang menggunakan R-22 dengan penambahan pre-cooling menunjukan nilai koefisien yang lebih besar yaitu rata-rata 3,943 dibandingkan dengan sistem yang menggunakan MC-22 dengan penambahan pre-cooling rata-rata nilai koefisien elektriknya yaitu 3,786. Hal ini disebabkan karena R-22 memiliki massa jenis refrigeran yang lebih besar dibandingkan dengan MC-22

Apabila dibandingkan dengan sistem yang menggunakan R22 tanpa menggunakan pre-cooling dengan R-22 yang dilengkapi dengan pre-cooling maka rata-rata nilai koefisien kinerja elektrik pada sistem yang menggunakan R-22 tanpa menggunakan pre-cooling adalah 4,151, dimana lebih tinggi dibandingkan dengan rata-rata nilai koefisien kinerja elektrik pada sistem yang menggunakan R-22 dengan pre-cooling yaitu 3,943. Hal ini disebabkan karena sistem yang di dilengkapi dengan pre-cooling membutuhkan arus listrik yang lebih besar dibandingkan dengan sistem yang tidak menggunakan pre-cooling.

\section{B. Kinerja Sistem Thermal vs Kapasitas Kondensasi}

Berikut ini adalah grafik $\mathrm{COP}_{\text {thermal }}$ (coefficient of performance) terhadap kalor yang dilepaskan oleh condenser (kapasitas kondensasi) apabila dibandingkan saat tidak menggunakan pre-cooling dansaat menggunakan precooling adalah sebagai berikut :

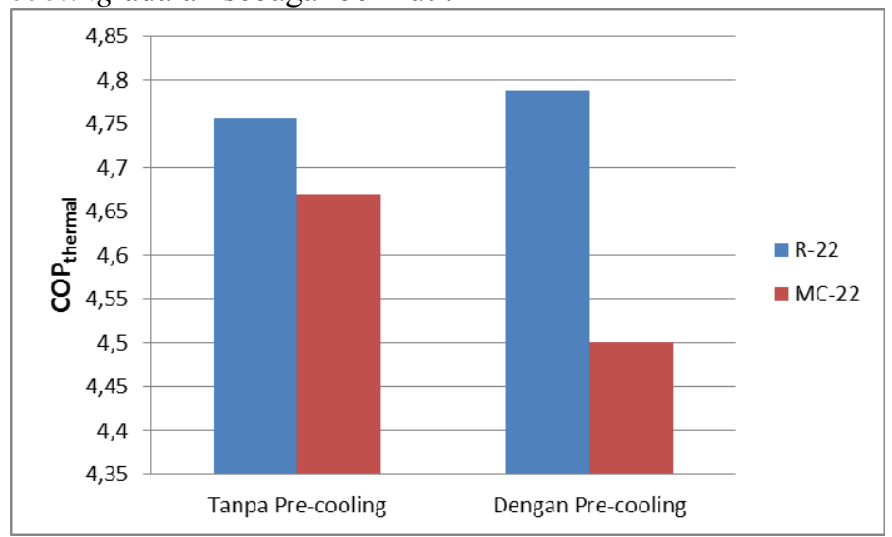

Gambar. 4. Perbandingan $\mathrm{COP}_{\text {thermal }}$ antara R-22, R-22 dengan penambahan pre-cooling, MC-22, dan MC-22 dengan penambahan pre-cooling.

Pada grafik tampak bahwa sistem yang menggunakan R-22 dengan penambahan pre-cooling menunjukkan nilai nilai koefisien yang lebih besar yaitu rata-rata 4,788 apabila dibandingkan dengan sistem yang menggunakan R-22 tanpa penambahan pre-cooling yaitu rata-rata nilai koefisien 4,756. Namun pada grafik tampak bahwa sistem yang menggunakan MC-22 tanpa penambahan pre-cooling memiliki $\mathrm{COP}_{\text {thermal }}$ yang lebih tinggi dengan rata-rata nilai 4,670, dibandingkan dengan sistem yang menggunakan MC-22 dengan penambahan pre-cooling 4,501. Hal tersebut terjadi karena dengan penambahan pre-cooling menimbulkan penurunan tekanan sehingga kompresor membutuhkan kerja yang lebih besar. 


\section{Effectiveness vs Number of Transfer Units}

Berikut ini adalah perbandingan grafik effectiveness terhadap number of transfer units pada sistem dengan penambahan pre-cooling antara R-22 yang dilengkapi precooling, dengan MC-22 yang dilengkapi pre-cooling. NTU yang dimaksud adalah nilai tak berdimensi untuk menganalisa heat exchanger apakah performanya baik atau tidak jika dilakukan variasi jenis refrigeran. Pada grafik tampak bahwa sistem yang menggunakan MC-22 memiliki nilai NTU lebih tinggi dengan rata-rata 2,043, dibandingkan dengan sistem yang menggunakan MC-22 dengan rata-rata NTU 0,1873. NTU dipengaruhi oleh effectiveness, bahwa NTU akan semakin menurun seiring dengan turunnya nilai effectiveness. Ditunjukan pada grafik sebagai berikut :

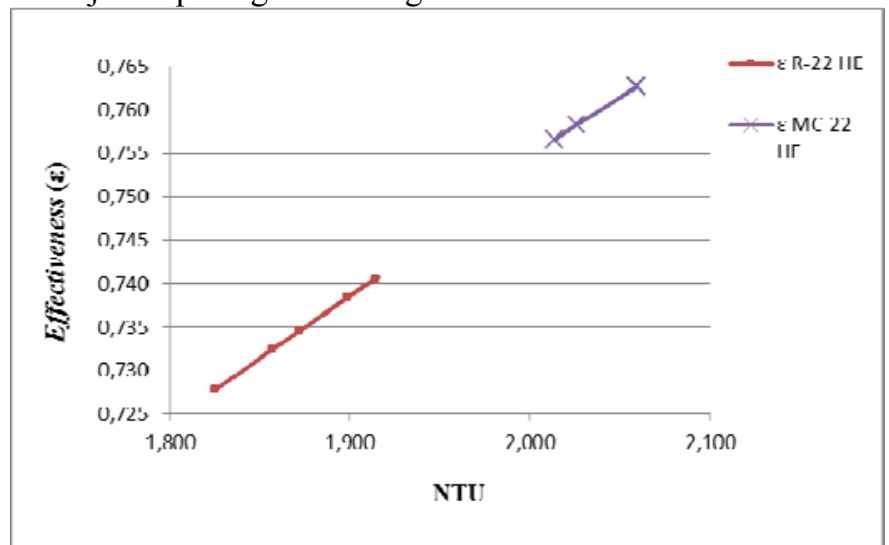

Gambar. 5. Perbandingan effectiveness terhadap number of transfer units antara R-22 yang dilengkapi pre-cooling, dengan MC-22 yang dilengkapi pre-cooling.

\section{KESIMPULAN}

Berdasarkan hasil analisis yang telah dilakukan, maka dapat disimpulkan pada penelitian ini sistem yang menggunakan MC-22 adalah yang mampu menghemat energi paling baik. Meskipun sistem yang menggunakan refrigeran primer R-22 memiliki kinerja sistem yang paling tinggi $(4,788)$ akan tetapi sistem tersebut dapat dikatakan tidak hemat energi dan tidak ramah lingkungan berdasarkan dari studi eksperimen dan analisa yang telah dilakukan.

\section{DAFTAR PUSTAKA}

[1] Aisbett, E. K., Pham, Q. T., 1998, "Natural Replacements for OzoneDepleting Refrigerants in Eastern and Southern Asia", International Journal of Refrigeration, Vol. 21, No. 1, pp. 18-28.

[2] Firdaus, Aneka., 2010, "Analisa Pengaruh Penggunaan Refrigeran Hidrkarbon Musicool-22 Pengganti Freon-22 Terhadap Kinerja Alat Air Conditionig", Seminar Tahunan Teknik Mesin, ISBN, Sriwijaya University, Palembang-Indonesia.

[3] Nasruddin, and Hamdi, E., 2003, "Natural Refrigerant in Indonesia:Chalange and Opportunity", presented in ISSM Delft, The Netherland. 